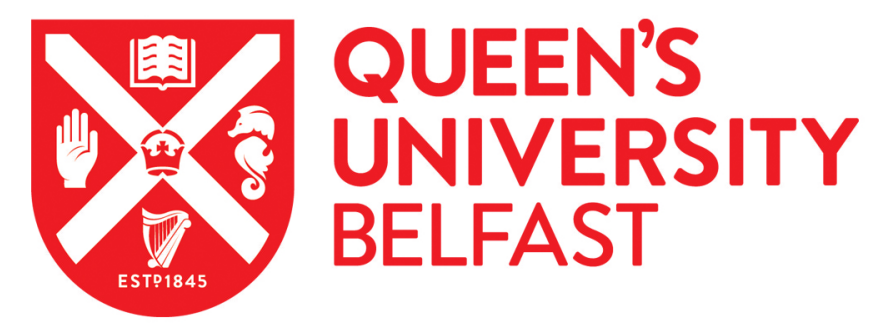

\title{
Effect of soil horizon stratigraphy on the microbial ecology of alpine paleosols
}

Young, J. M., Skvortsov, T., Kelleher, B. P., Mahaney, W. C., Somelar, P., \& Allen, C. C. R. (2019). Effect of soil horizon stratigraphy on the microbial ecology of alpine paleosols. Science of the Total Environment, 657, 11831193. https://doi.org/10.1016/j.scitotenv.2018.11.442

Published in:

Science of the Total Environment

Document Version:

Peer reviewed version

Queen's University Belfast - Research Portal:

Link to publication record in Queen's University Belfast Research Portal

Publisher rights

(C) 2018 Elsevier B.V.

This manuscript version is made available under the CC-BY-NC-ND 4.0 license http://creativecommons.org/licenses/by-nc-nd/4.0/,which permits distribution and reproduction for noncommercial purposes, provided the author and source are cited

\section{General rights}

Copyright for the publications made accessible via the Queen's University Belfast Research Portal is retained by the author(s) and / or other copyright owners and it is a condition of accessing these publications that users recognise and abide by the legal requirements associated with these rights.

Take down policy

The Research Portal is Queen's institutional repository that provides access to Queen's research output. Every effort has been made to ensure that content in the Research Portal does not infringe any person's rights, or applicable UK laws. If you discover content in the Research Portal that you believe breaches copyright or violates any law, please contact openaccess@qub.ac.uk. 


\section{Effect of soil horizon stratigraphy on 2 the microbial ecology of alpine 3 paleosols}

4

5

6

7

8

9

10

11

12

Jonathan M. Young ${ }^{1 *}$, Timofey Skvortsov², Brian P. Kelleher ${ }^{3}$, William C. Mahaney ${ }^{4}$, Peeter Somelar ${ }^{5}$, Christopher C.R. Allen ${ }^{1}$

${ }^{1}$ School of Biological Sciences, Queen's University Belfast, UK.

${ }^{2}$ School of Pharmacy, Queen's University Belfast, UK.

${ }^{3}$ School of Chemical Sciences, Dublin City University, Ireland.

${ }^{4}$ Quaternary Surveys, 26 Thornhill Ave, Thornhill, Ontario, Canada

${ }^{5}$ Department of Geology, Tartu University, Tartu, Estonia

*Author for correspondence.

\section{ABStract}

There is remarkable potential for research at the interface between the earth sciences and

environmental microbiology that may lead to advances in our understanding of the role of bacterial

communities in the surface or subsurface environment of our planet. One mainstay of sedimentary

classification is the concept of differential soil and/or paleosol horizons being the result of primarily

physical and chemical weathering, with relatively little understanding of how microbial communities

between these stratified horizons differ, if at all. In this study we evaluate the differences in

microbial community taxonomy and biogeochemical functional potential between stratified soil

horizons in an alpine paleosol environment using next-generation sequencing (NGS) shotgun

sequencing. Paleosols represent a unique environment to study the effect of differences soil horizon

environments on the microbial community due to their relative isolation, and the fact that three

distinct stratified soil horizons can be identified within the top $30 \mathrm{~cm}$ of the soil. This enables us to

assess variation in microbial community composition that will be relatively distinct from variation 
due to distance alone. We test the hypothesis that variation in soil community composition is linked to variation in the physical and chemical parameters that define stratigraphy. Multivariate statistical analysis of sequencing reads from soil horizons across five sampling sites revealed that 1223 microbial genera vary significantly and consistently in abundance across stratified soil horizons at class level. Specifically Ktedonobacter, Bacilli and Betaproteobacteria responded most strongly to soil depth. Alpha diversity showed a positive correlation with soil depth. Beta diversity, however, did not differ significantly between horizons. Genes involved in carbohydrate and nitrogen metabolism were found to be more abundant in Ah horizon samples. Closer inspection of carbohydrate metabolism genes revealed that genes involved in $\mathrm{CO}_{2}$ fixation, fermentation and saccharide metabolism decreased in abundance with depth while one-carbon metabolism increased down profile.

\section{INTRODUCTION}

Soil microbiology is a rapidly growing discipline, driven by the advances in high throughput sequencing and bioinformatic techniques. Microbiological studies on alpine soils to date have focused mainly on alpine forest, meadow and grassland soils (Ding et al., 2015; Yashiro et al., 2016; Zhang et al., 2013), comparatively little work has been carried out on cold, high altitude alpine soils and paleosols above the timberline (termed the alpine zone; Mahaney et al., 2016). Studies which have focused on soils/paleosols within the alpine zone, such as glacier forefields, have utilised techniques such as amplicon sequencing of the $16 \mathrm{~S}$ rRNA gene, restriction fragment length polymorphism (RFLP) and/or GeoChip microarrays (He et al., 2007) to assess microbial populations (Lazzaro et al., 2015; Zhang et al., 2013). These 
techniques are subject to significant limitations and potential biases, that can now be addressed using shotgun sequencing approaches coupled with bioinformatics.

Several studies have shown that the number of high alpine ecosystems may be expanding worldwide, due to an increase in glacier and ice cap thawing rates (King et al., 2011; Byers, 2008; Zemp et al., 2006) ), although there is a chance that increased temperature may reverse this trend by expanding forest to higher elevations (Körner and Paulsen 2004). Regardless, concerns are rising regarding the potential implications this may have for global atmospheric carbon levels as soils are a major carbon sink: soil organic matter contains approximately 3 times the size of the atmospheric pool of carbon and 4.5 times that of the biotic pool (Lal, 2004). Much more organic carbon exists in soils than in vegetation and the atmosphere combined, and the global carbon budget can be strongly influenced by changes in soil carbon content (Fierer et al, 2009; Serna-Chavez et al, 2013). Thawing permafrost in soils newly exposed to increased temperature may increase the rate at which soil microbes degrade soil organic carbon thus leading to a net increase in $\mathrm{CO}_{2}$ emissions (Davidson and Janssens, 2006). Additionally, the rate of methanogenesis could potentially increase, due to an increase in available metabolites for methanogens (such as acetate), generated as byproducts from organisms carrying out soil organic carbon degradation, which could lead to a net increase in methane emissions. Though these sediments are not completely anaerobic, soils in general become more anoxic with increasing depth (Yu et al., 2006). Additionally even in well oxygenated soils, methanogenesis can still occur due to the presence of anoxic microenvironments within soil aggregates (Fierer 2017). Without a more thorough understanding of the functional potential of the microbial communities present in these soils we cannot make predictions as to the possible effects of an increase in exposed alpine soils. 
The alpine paleosols studied in this report have developed from the weathering of parent material deposited during two periods following the last glaciation: The Bølling - Allerød warming of 15-12.8 ka and the Younger Dryas (YD) from 12.8- 11.5 ka (Mahaney et al., 2017). Moraines (deposits of glacial debris described here) from both pre-YD and YD time are evident at elevations greater than $2400 \mathrm{~m}$ above sea level in this region of France/Italy. The paleosols in these deposits are classified as Cryochrepts (i.e. cold-climate pedons) with Ah/Bw/Cox profiles over fresh undifferentiated, unweathered substrates. In geological terms the soils are identified as paleosols, and they possess distinct stratigraphy with 'classically' identified Ah/Bw/Cox soil horizons (Mahaney et al., 2013). The soils in this study are generally acidic with $\mathrm{pH}$ ranging from 4.0-6.0 (supplementary data file 1).

How microbial communities vary with respect to these soil horizons still remains an underexplored avenue of research in soil-paleosol microbial ecology. Of very few relevant published studies, those which compare soil-paleosol horizons either employed 16S rRNA gene amplicon sequencing (Baldrian et al., 2012; Mahaney et al. 2016) or focused specifically on certain functional enzymes, such as dehalogenation enzymes (Weigold et al., 2016). No studies have focused on changes in overall microbial community structure in relation to paleosol stratigraphy.

The alpine paleosols studied here present a unique opportunity to address this apparent gap in knowledge due to:

92 i. The fact that they possess well stratified horizons, being distinguishable horizons in 93 physical terms.

94 ii. The wealth of geochemical data already available for the region (e.g. Mahaney et al., 95 2016; Mahaney and Keiser, 2013). 
96 iii. Their isolation from the Anthropocene: as paleosols these soils are relatively

97 undisturbed by human activity until now, allowing us to assess the effect of $>10,000$ years of

98 isolated soil development. Their evolutionary history initiated in the Late Pleistocene coming up to their present state in the Late Holocene entitles them to the 'paleo'

100 designation.

There are a number of soil classification systems in current use (Eswaran, 2003), these varying by country and utility (e.g. assessing the suitability of the soil for agricultural use, or inferring its geological origin). In this study soils have been classified according to the United States Department of Agriculture (USDA) soil taxonomy system (USDA, 1999). In this system, a distinct soil horizon is classified as a layer of minerals and organic material, which differs from the parent material in mineral, physical, chemical, morphological, and biological features.

In this study, using high throughput shotgun sequencing, we first aimed to test the hypothesis that microbial communities vary significantly and consistently between stratified soil horizons in an alpine paleosol environment, both in terms of their taxonomic profile and functional potential. We then test the hypothesis that variations in the soil microbiome can be linked to variations in the physical and chemical properties of the soil horizons. Finally, we investigated which taxa and functional gene categories showed the strongest changes in abundance between soil horizons.

\section{Methods}

116 Sites were selected on the basis of air photo interpretation $(1: 20,000$ scale) of deposits.

117 Clasts embedded in major landform surfaces and profiles (Fig. 1) were sampled following 
excavation of sections to depths of $\sim 0.8 \mathrm{~m}$. Profiles extend to depths of $\sim 40-50 \mathrm{~cm} \pm 5 \mathrm{~cm}$.

Paleosol descriptions follow standard nomenclature (NSSC, 1995) and Birkeland (1999). The

'Cox' horizon designation, originally defined by Birkeland (1999), is applied to strata with

detectable levels of secondary Fe hydroxides and oxides, whereas ' $\mathrm{Cu}$ ' refers to

unweathered parent material (Hodgson, 1976). The 'Ah' horizon designation is applied

when surface color is stronger than 10YR 3/1, an indication of appreciable organic carbon accumulation (Canada Soil Survey Comm., 1998). Soil colors were assigned using Oyama and Takehara's (1970) soil colour chips. Bulk samples (250-300 g) were collected from paleosol horizons for particle size, clay mineral, geochemical and microbiological analyses.

DNA was extracted from alpine paleosol samples using a PowerSoil DNA extraction kit (Mo Bio). For each DNA extraction $0.25 \mathrm{~g}$ of sample was used per extraction, extractions were performed in triplicate and pooled. Extractions were performed according to the manufacturer's protocol with the following modifications: samples were homogenised using a FastPrep 120 cell disrupter system (Thermo-Fisher) at $5.5 \mathrm{~m} \cdot \mathrm{s}^{-1}$ for 2 minutes, rather than a standard bench top vortex. The eluted and pooled DNA was further purified via two rounds of ethanol precipitation; DNA solution was suspended in 3 volumes of ice cold $100 \%$ ethanol, 0.1 volumes $5 \mathrm{M}$ sodium acetate solution ( $\mathrm{pH} 5.2$ ) and $2 \mu \mathrm{L}$ of linearized polyacrylamide (LPA), the solution was then incubated overnight at $-20^{\circ} \mathrm{C}$ and centrifuged at $18000 \times \mathrm{g}$ at $4^{\circ} \mathrm{C}$ for 30 minutes. The supernatant was discarded and the pellet washed in $70 \%$ ice cold ethanol and again centrifuged at $18000 \times \mathrm{g}$ at $4^{\circ} \mathrm{C}$ for 5 minutes. Finally, the supernatant was discarded and the pellet allowed to air dry for 15 minutes before resuspension in $50 \mu \mathrm{L}$ molecular grade $\mathrm{H}_{2} \mathrm{O}$. Final DNA concentrations were measured using a Quantus Fluorometer (Promega) in conjunction with the Quantiflour DsDNA dye system 
141 (Promega). Soil physical and chemical variables were measured as previously described

142 (Mahaney et al., 2016)

Sequencing read quality, length and adapter contamination were initially assessed using Fastqc (Andrews, 2010). Adapter trimming was performed using bbduk from the bbtools package (Bushnell, 2015) using the provided library of Illumina adapters. Quality trimming was also performed using bbduk form the bbtools package, reads were trimmed to a minimum quality score of 20 over a sliding window of 10 bases, additionally the flag 'modulo $=5^{\prime}$ was used to remove trailing single odd numbered bases (i.e. the $301^{\text {st }}$ base in a 300bp library, or the $101^{\text {st }}$ base in $100 \mathrm{bp}$ library), which are common error bases in Illumina datasets. Read merging was performed using bbmerge from the bbtools package. Human DNA contaminants were removed by using removehuman.sh from the bbtools package. Briefly, raw reads are mapped onto a prebuilt index of the human genome which had been masked to hide 1) any low complexity repeat regions and 2) any regions which showed > $85 \%$ identity to any sequence in the Silva rRNA database (Quast et al., 2013) over a 70 basepair window. This method removes potential human DNA contamination while minimising false positive hits to low complexity regions and ribosomal RNA sequences

Assembly benchmarking was performed using three de-novo genome assemblers optimized for metagenomic data, Megahit (Li et al., 2016), SPAdes (Bankevich et al., 2012) (with the flag: - meta), and IDBA-UD (Peng et al., 2012), using kmers ranging from 27-127 in steps of 10. Benchmarking was performed against un-normalized raw reads and reads normalized to minimum kmer depth of 3 and maximum kmer depth of 100 for kmers of size 32. Normalization was performed using bbnorm form the bbtools package, with the flags $\min =3, \max =100, k=32$. Read recruitment for each assembly was estimated using bbmap 
with the flags $k=13$ vslow=t. Annotation of quality trimmed reads was achieved using Kaiju (Menzel et al., 2016). A database of all proteins from all bacteria, archaea, single celled eukaryotes and viruses in the NCBI non-redundant protein database (NCBI Resource Coordinators, 2017) was constructed using the makeDB.sh script supplied with Kaiju. Nucleotide reads were translated into amino acid sequence in all 6 reading frames and taxonomically annotated by alignment against this database using Kaiju, with a maximum of 5 mismatches allowed and a minimum bit score of 60 . Reads were projected onto all taxonomic ranks from phylum to species and per-sample abundances were compiled into single data tables for downstream statistical analysis using a custom bash script. Functional annotations were assigned by mapping NCBI accession IDs from the Kaiju analysis onto functional classifications from the SEED subsystems protein hierarchy (Overbeek et al., 2005) at levels 1, 2 and 3 using MEGAN 6 (Huson et al., 2016).

All taxonomic and functional annotations and read counts were concatenated and downstream analysis was performed using R 3.4.1 (R Core Team, 2011). Taxonomic and functional abundances were summed at each taxonomic and functional rank and normalized by dividing counts for each sample by the total number of reads that were annotated for that sample using the aggregate function. Prior to statistical analysis, taxonomic and functional abundance values were Hellinger transformed as described in Legendre and Gallagher, (2001) using the function decostand from the package vegan (Oksanen et al., 2016). Soil abiotic variables were log transformed and standardized such that each variable had a mean of zero and standard deviation of 1 across all samples. 
Euclidean distance dissimilarity matrices were produced for normalized abundance and abiotic variable tables using the vegdist function from vegan. Principal component analysis was performed using the capscale function in vegan, samples were plotted in two dimensional space using their first two principal components, plots were produced for taxonomic abundances at the class and genus levels, for functional abundances, and for soil abioitic variables. For taxonomic annotation tables, genus-level richness and ShannonWeaver diversity indices were computed using the diversity function from the package vegan. Beta diversity for each soil horizon was inferred for all taxonomic and functional ranks as the distance to the group centroid in Euclidean space using the betadisper function from the package vegan. Analysis of variance (ANOVA) tests were performed to test for similarities (ANOSIM) (Clarke, 1993) was performed on all samples grouped by biome type, significant.

\section{Data availability}



number PRJNA39461.

\section{Results}

\section{DNA EXTRACTION, SEQUENCING DATA QC AND PROCESSING}

Vertical sections of weathered sediment (paleosols) in a series of five moraines in the Guil river valley of the French Alps, (G1, G2, G3a, G9, and G11) were sampled at three discrete stratified soil horizons (Ah, Bw and Cox) and were classified as previously described (Mahaney et al., 2016; 2017) (Figure 1). The geology of these paleosols is an active area of glacial, cosmic and microbiological research as described in several related geological papers to date (Mahaney et al., 2013, 2016, 2017; Mahaney and Keiser, 2013).

Total DNA per gram of soil generally decreased with increasing depth, indicating a lower total biomass at lower depths in the soil profile (supplementary table S3). Average sequence read lengths were as expected (300bp), average sequence quality was found to be $>20$ for the full length of each read for all samples. Adapter contamination was also found to be low, on average $<1 \%$ per library. Although merging of the paired end reads was attempted, on average $<30 \%$ of reads could be merged, indicating that the average insert size of the sequencing libraries exceeded $600 \mathrm{bp}$, therefore downstream processing was performed on interleaved PE reads.

Attempts at assembly of the metagenomic libraries revealed generally poor assemblies (supplementary table S4) and a significant loss of information (i.e. the percentage of raw reads which could be mapped onto the assembly). Since the goal here was to characterize these soil samples in a general sense it was decided that the loss of information during assembly and 
overall poor assembly statistics were deemed unacceptable. Therefore annotation was performed using only the raw PE read files, since the reads were on average 300bp in length, a reasonable level of taxonomic resolution can still be obtained, and in most cases assignments could be made down to the genus level without much further loss of information (supplementary figure S1).

On average $\sim 80 \%$ of all reads could be assigned to at least the Phylum level, the functional gene assignment rates were significantly lower at ranging from $17-26 \%$ depending on the SEED subsystem level used. As taxonomic resolution increases so the number of reads which can be confidently assigned to a taxon decreases, with a significant drop-off in the number of reads which can be assigned to the species level, therefor for downstream analysis, the genus level was the minimum taxonomic rank which was analysed..

\section{TAXONOMIC / FUNCTIONAL ANNOTATION}

At the class level it is apparent that the community is dominated by four major taxa (Figure

2), the Actinobacteria, Alphaproteobacteria, Betaproteobacteria and Gammaproteobacteria

all of which are common genera of soil microbes which appear to be ubiquitous in soils (Barberán et al., 2014). The Actinobacteria account for roughly $30 \%$ of the total annotated reads in all samples. The Bacilli and Acidobacteriia also appear to be reasonably abundant, as might be expected for paleosols with low $\mathrm{pH}$ 4.0-6.0. Certain horizon dependent patterns

251 in the data also emerge even in these boxplots, for example, the Betaproteobacteria and samples while the Ktedonobacteria appear to be generally more abundant in the Ah horizon samples. 
Alpha diversity was estimated for each sample at each taxonomic level using the Shannon-

Weaver diversity index (Shannon and Weaver, 1964), Inverse Simpson diversity index

(Simpson, 1949) and genus-level richness (i.e. number of unique genera per sample). Linear

regression of alpha diversity measures against sample depth reveals a fairly strong, statistically significant linear relationship between soil depth and alpha diversity (Figure 3). Interestingly while richness appears to decrease with depth, the diversity indices appear to increase. Both inverse Simpson and Shannon diversity indices account for taxon abundances, where a lower value indicates more uneven taxon abundances, suggesting that while the number of unique genera decrease while moving down a soil profile, the relative abundances of these genera become more even.

In order to test the statistical significance of differences in community structure between horizons, ANOSIM (Figure 3) and Adonis tests (supplementary table S2) were applied. It was necessary to test for homogeneity of group dispersions, i.e. whether or not the multivariate spread of the samples from their group centroids are significantly different (Figure $\mathbf{3}$ panel B). Homogeneity of group dispersion tests were performed for samples grouped by both soil horizon and sample site, results were not statistically significant in any case, meaning that downstream ANOSIM tests may be interpreted confidently without any caveats. The results of both ANOSIM and Adonis tests indicate that soil horizon has a much stronger effect on microbial community than sampling site: the ADONIS R statistic is reasonably high for all ranks when grouped by soil horizon and much lower when grouped by sampling site, indicating that the effect is genuine. Statistical significance is strong with all ranks showing three star significance $(P<0.001)$ when grouped by soil horizon, apart from the phylum level which 
shows two star significance $(\mathrm{P}<0.01)$ (supplementary table $\mathrm{S} 3$ ). When grouped by sampling site, there is a marginally significant effect at the phylum level although this is not seen at lower levels of taxonomic resolution, or at the functional gene level.

\section{Correlations With Soll Abiotic Variables}

The effect of soil horizon classification on soil abiotic variables was also assessed (Figure 4). Out of the 27 variables which were assessed here [supplementary data file 1], 12 were found to correlate significantly with soil depth and between stratified soil horizons. These 12 include 5 of the 6 essential elements for life $(C, H, N, P, S)$, it can also be presumed that available oxygen also decreases with soil depth. Where $\mathrm{C}, \mathrm{N}$ and $\mathrm{P}$ were compered total rather than soluble levels were used, because we wanted to consider insoluble sources of these elements (e.g. lignin). Given this information, it is unsurprising that the total DNA per g of soil decreases with depth and that the microbial communities between soil horizons are significantly different from one another (ANOSIM significance $=3.9 \mathrm{e}^{-4}$ ) (Figure 3).

Conversely, the concentration of numerous elements important for life $\mathrm{Ca}, \mathrm{Cu}, \mathrm{Na}$, $\mathrm{K}$ and $\mathrm{Mn)}$ appears to increase with soil depth - perhaps due to leaching. This is typical during weathering of parent material, when the elements are realised they are leached down profile (Retallack, 2001). The exception is K that follows decreasing trend toward the parent rock. The $\mathrm{K}$ is most likely incorporated into secondary clay minerals like Illite, illite-smectite and/or illite-vermiculite (Mahaney et al., 2016).

Principle component analysis was performed on taxon abundances (at the class and genus levels), functional abundances (at SEED subsystems level 1) and abiotic variables (Figure 5), 
revealing strikingly similar patterns between samples in multivariate space. There is a clear and consistent separation of soil horizons along the first principal component axis in all cases. There is also a slight overlap between Bw and Cox horizons in the case of the Genus level abundance and chemical variables, indicating that the Bw and Cox horizons are less strongly differentiated from each other. This corresponds with the sedimentology - which indicates that the Bw horizon is only weakly differentiated and still developing (hence the w classification), and therefore it is not surprising that these data suggest a closer degree of similarity between population in the Bw and Cox horizons (Mahaney et al., 2013). In all cases, the first two principle component axes cumulatively explain $>70 \%$ of the total variation (> $80 \%$ in the case of the taxonomic variation).

In order to identify the taxa and functions which contribute most to the differences between soil horizons the Kruskal-Wallace $\mathrm{H}$ test (Kruskal and Wallis, 1952) for differences between groups was applied to taxonomic abundances at the class level, and functional abundances at level 1 Of the SEED subsystems hierarchy. For clarity, plots were only produced for taxa and functions which occurred at an abundance greater than $0.1 \%$ in at least one sample.

It is clear that the abundances of many classes of bacteria vary along the depth profile (Figure 6). Nine of the top ten most significantly variable taxa appear to increase with soil depth, while the only one which decreases are the Ktedonobacteria. Likewise, classes which are known to comprise many obligate and facultative anaerobes (the Bacilli, Clostridia and Negativicutes) increase significantly with depth. The Betaproteobacteria are one of the most abundant classes present in the dataset and show a near $3 \%$ increase in median abundance between the Ah and Cox horizons. A total of 57 Classes were shown to vary significantly between soil horizons, applying this analysis to genus level abundances revealed that 1223 
genera vary significantly between soil horizons. Overall, what has become clear from these data is that a large number taxa vary significantly and consistently between soil horizons over all six sample sites, even when measured at higher taxonomic ranks.

Similarly, many functional gene categories vary in abundance with respect to soil horizon, although the effect is much less pronounced than for taxon abundances, with only 6 major categories showing significant variation (Figure 7). Nitrogen metabolism and carbohydrate metabolism are the two which can be most obviously linked to ecosystem level processes. Both decrease with increasing depth, corresponding to the decrease in soil nitrogen and organic carbon with depth recorded by Mahaney, et al. (2016). The low measured N (supplementary data file 1) concentrations in these soils would suggest that the environment is extremely nitrogen limited. Therefore we would expect that Ammonia oxidation may be an extremely important component of the nitrogen cycle in these soils. Genes relating to central metabolism (i.e. metabolic pathways essential for organism survival) and secondary metabolism (i.e. pathways which are non-essential) show a near inverse relationship, with secondary metabolism decreasing with depth while central metabolism genes increase with depth. This may be explained by the fact that in lower soil horizons, where nutrients are less are selected against over time - core metabolism genes become more important.

Additionally, in the Ah horizon where $\mathrm{C} \mathrm{N}$ and $\mathrm{P}$ are more abundant we might expect antimicrobial secondary metabolites biosynthesis genes to be more prevalent due to the higher abundance of microbes competing for these nutrients. In lower soil horizons with less microbial activity, competition for nutrients is likely to be lower leading to a drop in the 
abundance of anti-microbial biosynthesis genes, although this cannot be confirmed from the results of this study. This does however suggest the possibility that nutrient-rich surface soil horizons may be ideal locations to screen for the presence of novel antimicrobial compounds and future work should endeavour to test this hypothesis. Fatty acid and isoprenoid synthesis genes are more abundant in the Ah horizon, this may be due to the fact these genes are heavily involved in cell membrane maintenance and manufacture (Kaneda, 1991), and may indicate that the Ah horizon hosts the most actively growing microbial cells. Finally, membrane transport related genes appear to be most abundant in the Cox horizons. The reason for this trend is not immediately obvious, though one could speculate that it may be connected to an increase in chemo-lithotrophic lifestyles in the lower mineral soil horizons where alternative electron donors (such as sulfide, ferric Iron or ammonia) must be transported across the cell membrane before they can be used by the cell for ATP synthesis (Peck 2003).

Carbohydrate metabolism is one of the largest SEED subsystem categories and contains many subcategories of genes which are linked to the carbon cycle, therefore carbohydrate metabolism genes were analyzed in more detail (Figure 8). After multiple test corrections were applied 5 categories within carbohydrate metabolism show significant variation. Poly, mono, di and oligo saccharide metabolism genes all decrease moving down the soil profile, as do carbon dioxide fixation genes. This is hardly surprising due to the fact that organic carbon, and carbon dioxide are generally present at higher concentrations in upper soil horizons. However, one-carbon metabolism genes appear to increase with soil depth, as might be expected given the importance of the methane cycle in low organic carbon environments (Serrano-Silva et al., 2014). A picture of the carbon cycle in these soils then begins to emerge whereby organic carbon is primary energy and provides carbon sources for many microbes in 
upper soil horizons as might be expected, while organisms in lower soil horizons gain energy and carbon by utilizing reduced one-carbon compounds (e.g. methane) as energy sources which are liberated from the anaerobic turnover of waste products from the upper horizons.

\section{Discussion}

It is clear that the abundances of many bacterial vary consistently between stratified soil horizons (Figure 6). We found that the Ktedonobacter showed the largest differential abundance between stratified soil horizon and was generally most abundant in the Ah horizons, members of this class are thought to be aerobic filamentous, spore-forming, grampositive, heterotrophic bacteria (Yabe et al. 2017). Conversely, many classes of obligate and facultative anaerobes decreased in abundance with soil depth (eg. the Bacilli, Clastridiales) (Figure 3), suggesting a strong influence of oxygen availability on the community composition. Interestingly, the most abundant classes of microbes across all samples (eg: Acinobacteria, Proteobacteria) (Figure 2) did not show a statistically significant variation in abundance between soil horizons (Figure 6), perhaps suggesting that the more successful microbes in these environments are ones with mixotrophic lifestyles who can adapt to variable conditions between soil horizons.

When comparing functional profiles between soil horizons, differences in certain biogeochemical cycling genes become clear. It is evident that many gene abundances correlate either positively or negatively with depth, which is understandable given that most key nutrients will vary down profile. Nitrogen metabolism appears to decrease with increasing depth, and likewise, carbohydrate metabolism genes appear to be significantly 
more abundant in the Ah horizon, corresponding to the zone of highest organic carbon turnover (evident from CNP measurements, Mahaney et al., 2016). Taking a more detailed look at carbohydrate metabolism (Figure 8) revealed that there are significant variations even within this category. Carbon dioxide (autotrophy) and central carbohydrate metabolism genes appear to be relatively abundant in the Ah horizon, while genes for other one-carbon metabolism becomes more abundant in the Cox horizon. This is consistent with increasing abundance of methane (associated with both methylotrophy and methanogenesis) turnover processes in deeper soils (Dunfield, 2007). This is likely due to the fact that, as complex plant polymers are broken down by microbes in the upper soil horizons, reduced carbon compounds are produced as waste products and filter down to the lower horizons where they are then utilized by methylotrophic microbes.

It should be noted that there is significant co-linearity between the many abiotic and biotic variables measured and compared here. As an example, looking specifically at almost all other abiotic and biotic parameters correlate with soil depth (in $\mathrm{cm}$ ) to some degree (Figure 5). Therefore it was not possible to investigate and compare correlations between individual taxa/functions and abiotic variables as disentangling this co-linearity to reveal the true source of variation is not possible without carefully designed laboratory experiments to control for the effect of specific co-linear variables identified here. Indeed, any attempt to do so may be statistically dubious and may therefore be considered as an example of "p-hacking" (Head et al., 2015). However, this analysis makes it abundantly clear that soil horizon matters: in terms of chemistry, taxonomy and functionality of the community. 
There are several important caveats to the results presented here that must also be considered. Firstly, metagenomes are not expected to be static over time, so caution must be taken when making broad statements about a microbial community. In extreme cases, we might expect drastic changes in microbial community structure to (Mahaney et al., 2017). Otherwise, previous studies have established that temporal variation within soil microbiomes is generally much lower than spatial variation (Lauber et al., 2013), so the patterns observed here are likely to persist across seasons, at least in the short term. Secondly, for any enzyme-catalysed processes to occur, transcription and translation of protein coding genes are essential requirements. Therefore, a positive relationship between the abundance of gene or transcripts and corresponding process rate is not always necessarily true, though it is often presumed. Rocca et al., (2015) indicated that functional gene abundances are only weakly correlated to process rates, but are consistently correlated across multiple environments. Finally, the relatively low depth of sequencing per sample means that complete genomes cannot be resolved, (a common limitation for diverse soil metagenomes (Nesme et al. 2016) and annotations are based on 300bp fragments. Much more robust results could be obtained with more complete genomes and functional genes, allowing investigation of functional genes in their genomic context, and analysis of complete metabolic pathways within certain species. The relatively short read length used here may be useful for taxonomic classification but full length genes are preferable for functional annotation. Despite this limitation, there is a growing body of evidence to suggest that shallower sequencing across many samples with suitable replication levels is sufficient to answer key questions about microbial ecology (Knight et al., 2012). 
Fundamentally we know that soil stratigraphy is a function of soil chemistry (USDA 1999).

Our full metagenome data, for the first time, show that soil stratigraphy is strongly correlated with variation in microbial community composition - as shown in figures 3 and 5 . Furthermore we find that the variation seen between stratified soil horizons is greater than the variation seen between soil sampling sites when taken as a whole (Figure 3).

Ultimately, the physical and chemical properties of a soil are the true drivers of microbial diversity and soil horizons are a useful method for categorizing soils with similar physicochemical characteristics. While the gene analysis presented here has provided an overview of microbial community structure and functionality in alpine soils, it has also highlighted a need for more specific methods in order to make definitive statements about biogeochemical processes occurring between soil horizons. The use of more specific and informative functional gene ontologies or the use of meta-transcriptomic information will certainly add a further level of understanding to this field. One correlation that we did not investigate in this study, is the relationship between oxygen concentration and/or redox potential with metagenome composition down profile. In general we would expect these to decrease with depth. Clearly there is abundant microbial activity in the sediments, and oxygen - as the ultimate acceptor - would certainly become limiting to microbial metabolism within a cm or two of the Ah horizon (Birkeland, 1999).

\section{CONCLUSION}

In conclusion, our study begins to demonstrate a clear relationship between the physicochemical parameters that are typically used to define soil pedons, and parallel the structure of complex microbial communities. The ability to do so has only become available to us in 
recent years due to the advent of shotgun sequencing and metagenomic analysis. The limitations of culture-dependant microbial analysis, have previously not allowed any such connection to be established. However, in this study some dependency is evident: the reduction between organic carbon availability and the related genetic profile of functional genes involved in C1 turnover is especially clear and is quite rational. The results here may lead us to consider that the formation of paleosol horizons is inextricably linked to the biological, not just physical and chemical transformations that occur. Critically, we emphasise here a key finding in this study - that variation in microbial gene populations between palesol samples sites, sometimes hundreds of metres apart, is significantly less than that seen between soil pedons, just centimetres apart at specific sample sites. This remarkable metagenome diversity may be exploited for gene mining applications.

\section{Acknowledgements}

We acknowledge the REMEDIATE KTN (CCRA, BK), Invest Northern Ireland (TS), and Quaternary Surveys (WM) for financial support.

\section{REFERENCES}

Andrews S. (2010). FastQC: a quality control tool for high throughput sequence data. http://www.bioinformatics.babraham.ac.uk/projects/fastqc. ๆ

Baldrian P, Kolařík M, Štursová M, Kopecký J, Valášková V, Větrovský T, et al. (2012). Active and total microbial communities in forest soil are largely different and highly stratified during decomposition. ISME J 6: 248-258.ๆ 
Bankevich A, Nurk S, Antipov D, Gurevich AA, Dvorkin M, Kulikov AS, et al. (2012). SPAdes: A New Genome Assembly Algorithm and Its Applications to Single-Cell Sequencing. J Comput Biol 19: 455477.

Barberán A, Ramirez KS, Leff JW, Bradford MA, Wall DH, Fierer N. (2014). Why are some microbes more ubiquitous than others? Predicting the habitat breadth of soil bacteria. Ecol Lett 17: 794-802.

Birkeland, P.W., 1999. Soils and Geomorphology. Oxford University Press, Oxford, UK, p. 430.ף

Bushnell B. (2015). BBMap short-read aligner, and other bioinformatics tools. Available from sourceforge net/projects/bbmap.ๆ

Byers AC. (2008). An assessment of contemporary glacier fluctuations in Nepal's Khumbu Himal using repeat photography. Himal J Sci 4: 21-26.ๆ

Canada Soil Survey Committee (CSSC), (1998). The Canadian System of Soil Classification, 637. NRC Research Press, Ottawa, Canada, p. 187.ף

Clarke KR. (1993). Non-parametric multivariate analyses of changes in community structure. Austral Ecol 18: 117-143. ๆ

Davidson EA, Janssens IA. (2006). Temperature sensitivity of soil carbon decomposition and feedbacks to climate change. Nature 440: 165-173. ๆ

Ding J, Zhang Y, Deng Y, Cong J, Lu H, Sun X, et al. (2015). Integrated metagenomics and network analysis of soil microbial community of the forest timberline. Sci Rep 5: 7994.

Dunfield, PF. (2007). 10 The Soil Methane Sink. Greenhouse gas sinks, p.152.ๆ

Fierer N, Strickland MS, Liptzin D, Bradford MA, \& Cleveland CC. 2009. Global Patterns in Belowground Communities. Ecology Letters 12: 1238-49.ף

Fierer N. (2017). Embracing the unknown: disentangling the complexities of the soil microbiome. Nat Rev Microbiol 15: 579-590.ๆ 
Head ML, Holman L, Lanfear R, Kahn AT, Jennions MD. (2015). The extent and consequences of phacking in science. PLoS Biol 13: e1002106. ๆ

521

522

523

524

525

526

527

528

529

530

531

532

533

534

535

536

537

538

539

540

541

542

550

551

552

553

He S, Wurtzel O, Singh K, Froula JL, Yilmaz S, Tringe SG, et al. (2010). Validation of two ribosomal RNA removal methods for microbial metatranscriptomics. Nat Methods 7: 807-812.

Hodgson, JM. (1976). Soil Survey Field Handbook d Soil Survey Tech, Monograph, No. 5. 773.

Rothamsted Experimental Stn, Harpenden, Herts, p. 99.ๆ

Huson DH, Beier S, Flade I, Górska A, El-Hadidi M, Mitra S, et al. (2016). MEGAN Community Edition Interactive Exploration and Analysis of Large-Scale Microbiome Sequencing Data. PLOS Comput Biol 12: e1004957.ף

Kaneda T. (1991). Iso- and anteiso-fatty acids in bacteria: biosynthesis, function, and taxonomic significance. Microbiol Rev 55: 288-302. ๆ

King AJ, Karki D, Nagy L, Racoviteanu A, Schmidt SK. (2011). Microbial biomass and activity in high elevation ( $>5100$ meters) soils from the Annapurna and Sagarmatha regions of the Nepalese Himalayas. Himal J Sci 6: 11-18

Knight R, Jansson J, Field D, Fierer N, Desai N, Fuhrman JA, et al. (2012). Unlocking the potential of metagenomics through replicated experimental design. Nat Biotechnol 30: 513-20.ๆ

Körner, Christian, and Jens Paulsen. (2004). A World-Wide Study of High Altitude Treeline Temperatures. Journal of Biogeography 31: 713-32.ๆ

Kruskal WH, Wallis WA. (1952). Use of ranks in one-criterion variance analysis. J Am Stat Assoc 47: 583-621.ๆ

Lal, R. (2004). Soil carbon sequestration impacts on global climate change and food security. Science 304: 1623-1627.

Lauber CL, Ramirez KS, Aanderud Z, Lennon J, Fierer N. (2013). Temporal variability in soil microbial communities across land-use types. ISME J 7: 1641-1650.ๆ 
Lazzaro A, Hilfiker D, Zeyer J. (2015). Structures of Microbial Communities in Alpine Soils: Seasonal and Elevational Effects. Front Microbiol 6: 1330.ף

Legendre P, Gallagher ED. (2001). Ecologically meaningful transformations for ordination of species data. Oecologia 129: 271-280.ๆ

Li D, Luo R, Liu CM, Leung CM, Ting HF, Sadakane K, Yamashita H, Lam TW. (2016). MEGAHIT v1. 0: A fast and scalable metagenome assembler driven by advanced methodologies and community practices. Methods102: 3-11.

Mahaney WC, Keiser L. (2013). Weathering rinds-unlikely host clasts for an impact- induced event. Geomorphology 184: 74-839

Mahaney, WC, Somelar, P, West A, Krinsley D, Allen CCR, Pentlavalli P, Young JM, Dohm JM, LeCompte M, Kelleher B, Sean J, Pulleyblank C, Dirszowsky R, Costa P. (2017) Evidence for cosmic airburst/impact in the Western Alps archived in Late Glacial Paleosols. Quaternary International, 438: 68-80.ๆ

Mahaney WC, Keiser L, Krinsley DH, Pentlavalli P, Allen CCR, Somelar P, et al. (2013). Weathering rinds as mirror images of paleosols: examples from the Western Alps with correlation to Antarctica and Mars. J Geol Soc London 2012: 150.

Mahaney WC, Somelar P, Dirszowsky RW, Kelleher B, Pentlavalli P, McLaughlin S, et al. (2016). A Microbial Link to Weathering of Postglacial Rocks and Sediments, Mount Viso Area, Western Alps, Demonstrated through Analysis of a Soil/Paleosol Bio/Chronosequence. Journal of Geology. 124: 149-169.ๆ

Menzel P, Ng KL, Krogh A, Marth G, Lipman D. (2016). Fast and sensitive taxonomic classification for metagenomics with Kaiju. Nat Commun 7: 11257.ๆ

Mitra S, Rupek P, Richter DC, Urich T, Gilbert JA, Meyer F, Wilke A, Huson DH. (2011) Functional analysis of metagenomes and metatranscriptomes using SEED and KEGG. BMC bioinformatics. 12: S21.

National Soil Survey Center (NSSC), 1995. Soil Survey Laboratory Information Manual. Soil Survey Investigations Report No. 45. Version 1.00. USDA, Washington, DC., p. 3059 
592 NCBI Resource Coordinators. (2017). Database Resources of the National Center for Biotechnology

593 Information. Nucleic Acids Res 45: D12-D17.ๆ

594

595

Neira, J., Ortiz, M., Morales, L., \& Acevedo, E. (2015). Oxygen diffusion in soils: Understanding the

596

factors and processes needed for modeling. Chilean journal of agricultural research 75: 35-44.

597

Nesme J, Achouak W, Agathos SN, Bailey M, Baldrian P, Brunel D, et al. (2016). Back to the Future of 599

Soil Metagenomics. Front Microbiol 7: 73.ף

600

601

Oksanen J, Blanchet FG, Kindt R, Legendre P, Minchin PR, O'hara RB, Simpson GL, Solymos P, Stevens

602

$\mathrm{MH}$, Wagner H (2011). vegan: Community ecology package. R package version. 2011:117-8.

603

604

Overbeek R, Begley T, Butler RM, Choudhuri J V, Chuang H-Y, Cohoon M, et al. (2005). The

605

Subsystems Approach to Genome Annotation and its Use in the Project to Annotate 1000 Genomes.

606

Nucleic Acids Res 33: 5691-5702.ๆ

607

608

Oyama, M., Takehara, H., (1970). Standard Soil Color Charts. Japan Research Council for Agriculture,

Forestry and Fisheries, Tokyo, Japan.

610

Peck Jr, H. D. (1968). Energy-coupling mechanisms in chemolithotrophic bacteria. Annual Reviews in

Microbiology 22: 489-518.ๆ

613

Peng Y, Leung HCM, Yiu SM, Chin FYL. (2012). IDBA-UD: a de novo assembler for single-cell and

Quast C, Pruesse E, Yilmaz P, Gerken J, Schweer T, Yarza P, et al. (2013). The SILVA ribosomal RNA gene database project: improved data processing and web-based tools. Nucleic Acids Res 41: D590D596.ๆ

R Core Team. (2011). R: A Language and Environment for Statistical Computing. R Found Stat

Retallack GJ, (2001). Soils of The Past: An Introduction to Paleopedology, 2nd ed., Blackwell, Oxford, 
Rocca JD, Hall EK, Lennon JT, Evans SE, Waldrop MP, Cotner JB, et al. (2015). Relationships between protein-encoding gene abundance and corresponding process are commonly assumed yet rarely observed. ISME J 9: 1693-9.ๆ

Serna-Chavez HM, Fierer N, van Bodegom PM. (2013). Global drivers and patterns of microbial abundance in soil. Glob Ecol Biogeogr 22: 1162-1172.ๆ

Serrano-Silva N, Sarria-Guzan Y, Dendooven L, Luna-Guido M. (2014). Methanogenesis and Methanotrophy in Soil: A Review. Pedosphere 24: 291-307.ๆ

Shannon CE, Weaver W. (1964). The mathematical theory of communication. University of Illinois Press.

Simpson, E.H. (1949). Measurement of diversity. Nature.ๆ

Tukey JW (John W. (1977). Exploratory data analysis. Addison-Wesley Pub. Co.ๆ

USDA. (1999). Soil taxonomy: A basic system of soil classification for making and interpreting soil surveys. 2nd edition. $\emptyset$

Weigold P, El-Hadidi M, Ruecker A, Huson DH, Scholten T, Jochmann M, et al. (2016). A metagenomic-based survey of microbial (de)halogenation potential in a German forest soil. Sci Rep 6: 28958.ๆ

Yabe S, Sakai Y, Abe K, Yokota A. (2017). Diversity of Ktedonobacteria with Actinomycetes- Like Morphology in Terrestrial Environments. Microbes Env 32: 61-70.ๆ

Yashiro E, Pinto-Figueroa E, Buri A, Spangenberg JE, Adatte T, Niculita-Hirzel H, et al. (2016). Local Environmental Factors Drive Divergent Grassland Soil Bacterial Communities in the Western Swiss Alps. Appl Environ Microbiol 82: 6303-6316.ๆ

Yu, K., Faulkner, S. P., \& Patrick Jr, W. H. (2006). Redox potential characterization and soil greenhouse gas concentration across a hydrological gradient in a Gulf coast forest. Chemosphere 62: 905-914. ๆ

Zemp M, Haeberli W, Hoelzle M, Paul F. (2006). Alpine glaciers to disappear within decades? Geophys Res Lett 33: L13504ף 
Zhang Y, Lu Z, Liu S, Yang Y, He Z, Ren Z, et al. (2013). Geochip-based analysis of microbial

Figure 1: Overview of Sampling sites and soil stratigraphy. Panel A: Satellite map of sampling area. Panel B: Stratigraphy of soil profiles for each sample (from Mahaney et al., 2016). Sampling sites are shown at the top of each profiles, depth in centimeters is displayed on the left and soil horizon classification is displayed on the right of each profile.

Figure 2: Boxplot showing the relative abundances of the 20 most abundant Taxa across all samples at the Class level. Jittered points overlaid on boxplots represent individual sample and are coloured by sample soil horizon classification. The bottom and top of the boxes represent the first and third quartiles, with the central band representing the median, whiskers represent 1.5 times the interquartile range according to Tukey's schematic boxplot method (Tukey, 1977)

Figure 3: Diversity analysis of alpine soils. Panel A: Alpha diversity plots for taxonomic abundance tables at each taxonomic level. Y axis represents inverse Simpson diversity index, Shannon-Weaver diversity index, and Genus level richness (i.e. the number of unique genera detected per sample) respectively. $X$ axis represents depth in $\mathrm{cm}$ of soil sample. Blue lines represent linear regressions, shaded area represents the $95 \%$ confidence interval for the regression analysis. $\mathrm{R}^{2}$ values and $\mathrm{P}$-values for linear regressions along with significance codes are displayed for each plot. Panel B: homogeneity of group dispersions for samples grouped by soil horizon, $\mathrm{Y}$ axis represents distance to the group centroid in $2 \mathrm{~d}$ Euclidean space, standard error of the mean across all samples, analysis of variance (ANOVA) test $P$ 
value for differences between soil horizons value is displayed on the plot. Panel C: Boxplot of analysis of similarities (ANOSIM) results, $\mathrm{Y}$ axis represents ranked order of dissimilarities ANOSIM R statistic and significance level are shown on the plot, significance of the R statistic was assessed by permutation for 9999 replicates. The bottom and top of the boxes represent the first and third quartiles, with the central band representing the median, whiskers represent 1.5 time the interquartile range according to Tukeys schematic boxplot method (Tukey, 1977).

Figure 4: Analysis of effect of paleosol depth and paleosol horizon on paleosol abiotic variables. Panel A: Spearmans rank correlation matrix for pairwise correlations between soil geochemical variables. Points are coloured and scaled according to the value of the correlation coefficient, only correlations with a $\mathrm{P}$ value $<0.05$ are displayed. Variables which correlate significantly with soil depth are highlighted in red. PanelB: Boxplots of geochemical variables which vary significantly between stratified soil horizons. The bottom and top of the boxes represent the first and third quartiles, with the central band representing the median, whiskers represent 1.5 time the interquartile range according to Tukeys schematic boxplot method (Tukey, 1977).

Figure 5: PCoA plots of abundance tables at each taxonomic and functional rank. Constrained analysis of principal components was performed on dissimilarity matrices using the function capscale from the package Vegan (Oksanen et al., 2016) in $R$ version 3.4.1 ( $R$ Core Team, 2011). In each case the $x$ and $y$ axis represent the first and second principal component axis respectively. Points are coloured by soil horizon and the convex hulls are drawn and highlighted for each horizon grouping.

Figure 6: Boxplots showing relative abundance of microbial classes which differed significantly between soil horizons. Relative abundance is expressed as a percentage of the total annotated reads. 
representing the median, whiskers represent 1.5 time the interquartile range according to Tukey's boxplot method (Tukey, 1977). All data points are also plotted as points.

713 Figure 7: Boxplots of relative abundance of SEED level 1 functional categories. Relative abundance is 714 expressed as a percentage of the total annotated reads. The bottom and top of the boxes represent 715 the first and third quartiles, with the central band representing the median, whiskers represent 1.5 716 times the interquartile range according to Tukey's boxplot method (Tukey, 1977). All data points are 717 also plotted as jittered points.

718 Figure 8: Abundance of SEED level 2 categories related to carbon metabolism. Relative abundance is expressed as a percentage of the total annotated reads. The bottom and top of the boxes represent the first and third quartiles, with the central band representing the median, whiskers represent 1.5 time the interquartile range according to Tukey's boxplot method (Tukey, 1977). All data points are also plotted as points. 

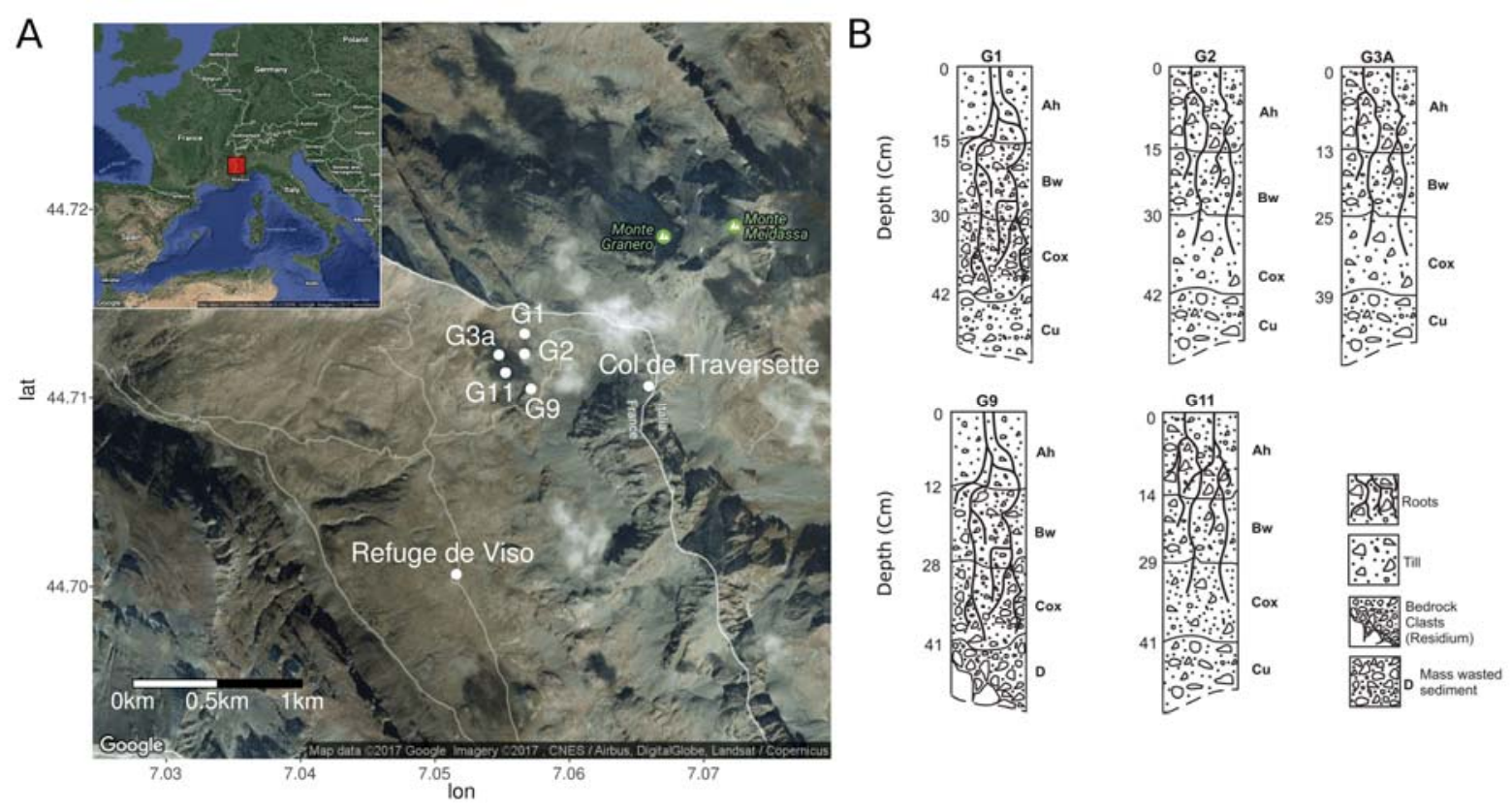

Figure 1: Overview of Sampling sites and soil stratigraphy. Panel A: Satellite map of sampling area. Panel B: Stratigraphy of soil profiles for each sample (from Mahaney et al., 2016). Sampling sites are shown at the top of each profiles, depth in centimetres is displayed on the left and soil horizon classification is displayed on the right of each profile.

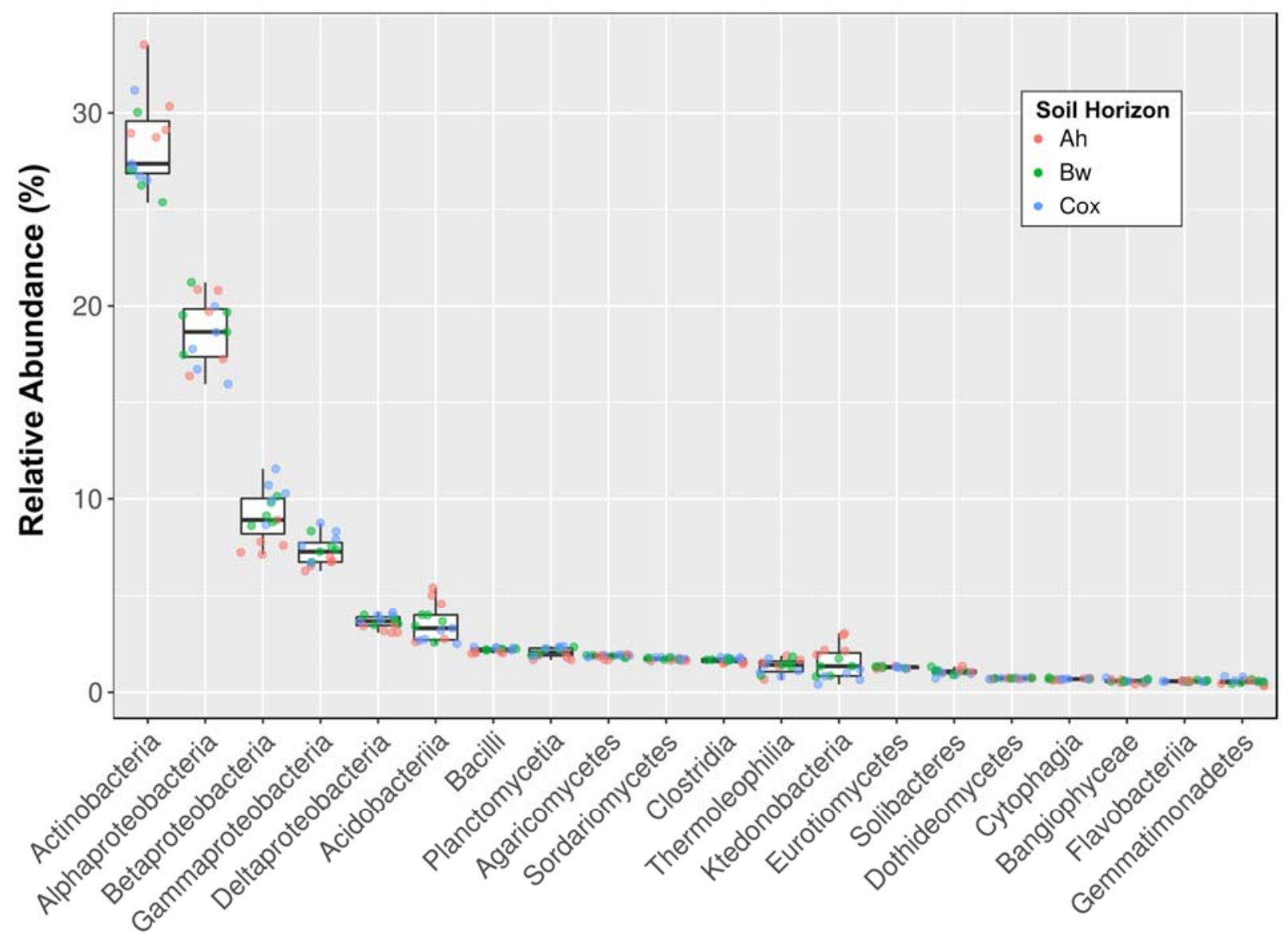

Taxon (Class Level) 
Figure 2: Boxplot showing the relative abundances of the 20 most abundant Taxa across all samples at the Class level. Jittered points overlaid on boxplots represent individual sample and are coloured by sample soil horizon classification. The bottom and top of the boxes represent the first and third quartiles, with the central band representing the median, whiskers represent 1.5 times the interquartile range according to Tukey's schematic boxplot method (Tukey, 1977)
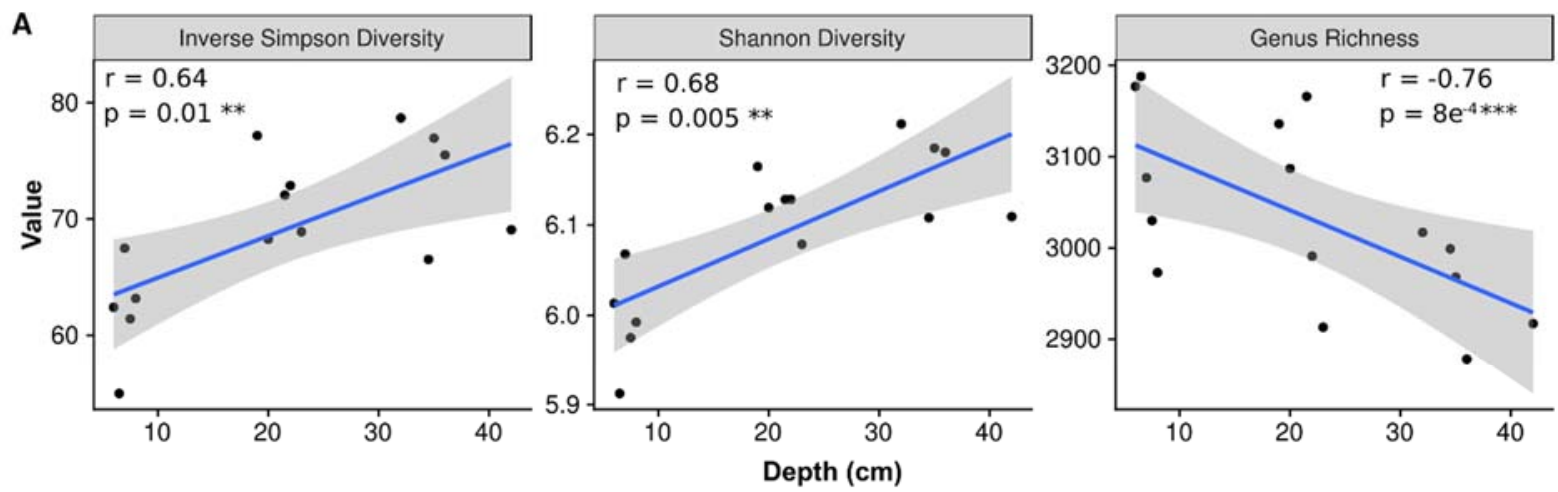

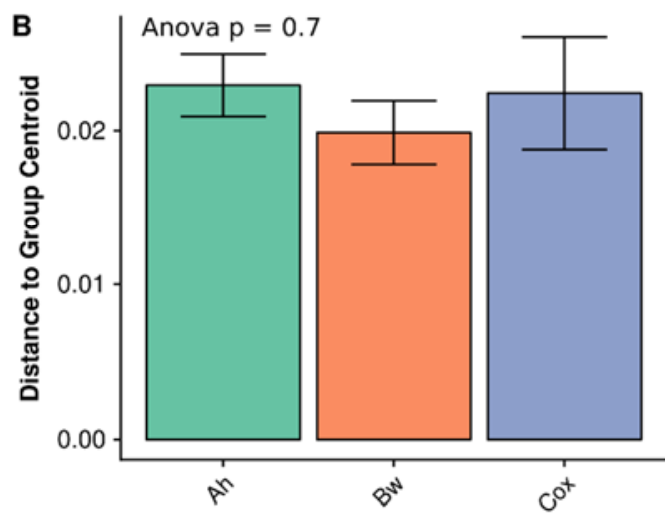

Soil Horizon
C

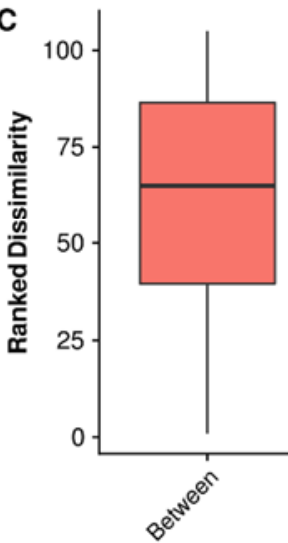

ANOSIM R $=0.53$ Significance $=3.9 \mathrm{e}^{-4 * * *}$

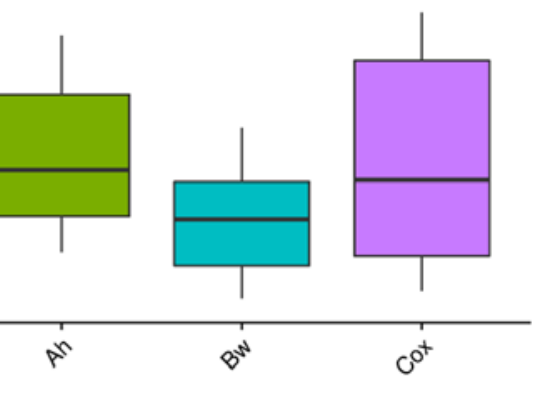

Group

Figure 3: Diversity analysis of alpine soils. Panel A: Alpha diversity plots for taxonomic abundance tables at each taxonomic level. Y axis represents inverse Simpson diversity index, Shannon-Weaver diversity index, and Genus level richness (i.e. the number of unique genera detected per sample) respectively. $X$ axis represents depth in $\mathrm{cm}$ of soil sample. Blue lines represent linear regressions, shaded area represents the $95 \%$ confidence interval for the regression analysis. $\mathrm{R}^{2}$ values and $\mathrm{P}$-values for linear regressions along with significance codes are displayed for each plot. Panel B: homogeneity of group dispersions for samples grouped by soil horizon, $Y$ axis represents distance to the group centroid in $2 d$ Euclidean space, standard error of the mean across all samples, ANOVA test $P$ value for differences between soil Horizons value is displayed on the plot. Panel C: Boxplot of ANOSIM results, $Y$ axis represents ranked order of dissimilarities ANOSIM R statistic and significance level are shown on the plot, significance of the R statistic was assessed by permutation for 9999 replicates. The bottom and top of the boxes represent the first and third quartiles, with the central band representing the median, whiskers represent 1.5 time the interquartile range according to Tukeys schematic boxplot method (Tukey, 1977). 
A

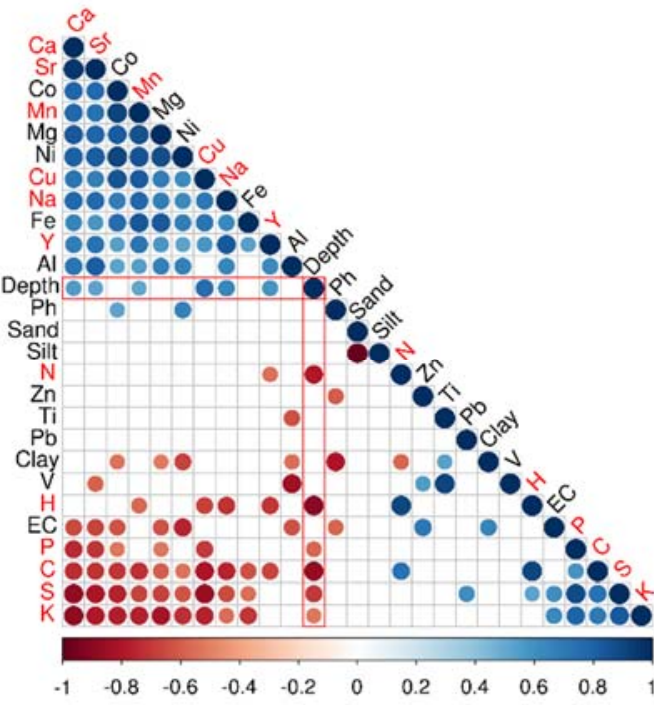

Spearmans Rank Correlation Coefficient
B

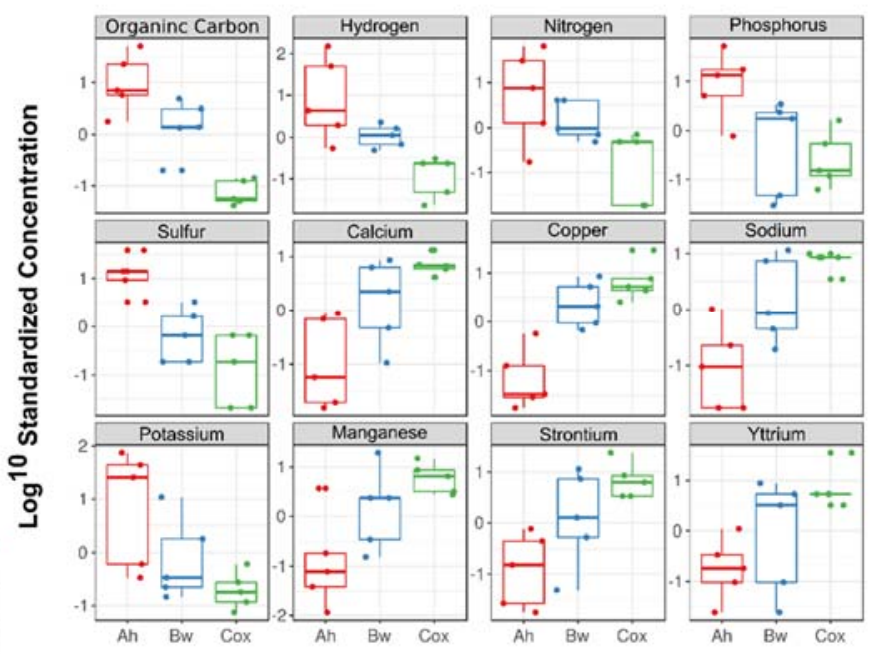

Soil Horizon

Figure 4: Analysis of effect of paleosol depth and paleosol horizon on paleosol abiotic variables. Panel A: Spearmans rank correlation matrix for pairwise correlations between soil geochemical variables. Points are coloured and scaled according to the value of the correlation coefficient, only correlations with a $\mathrm{P}$ value $<0.05$ are displayed. Variables which correlate significantly with soil depth are highlighted in red. PanelB: Boxplots of geochemical variables which vary significantly between stratified soil horizons. The bottom and top of the boxes represent the first and third quartiles, with the central band representing the median, whiskers represent 1.5 time the interquartile range according to Tukeys schematic boxplot method (Tukey, 1977). 

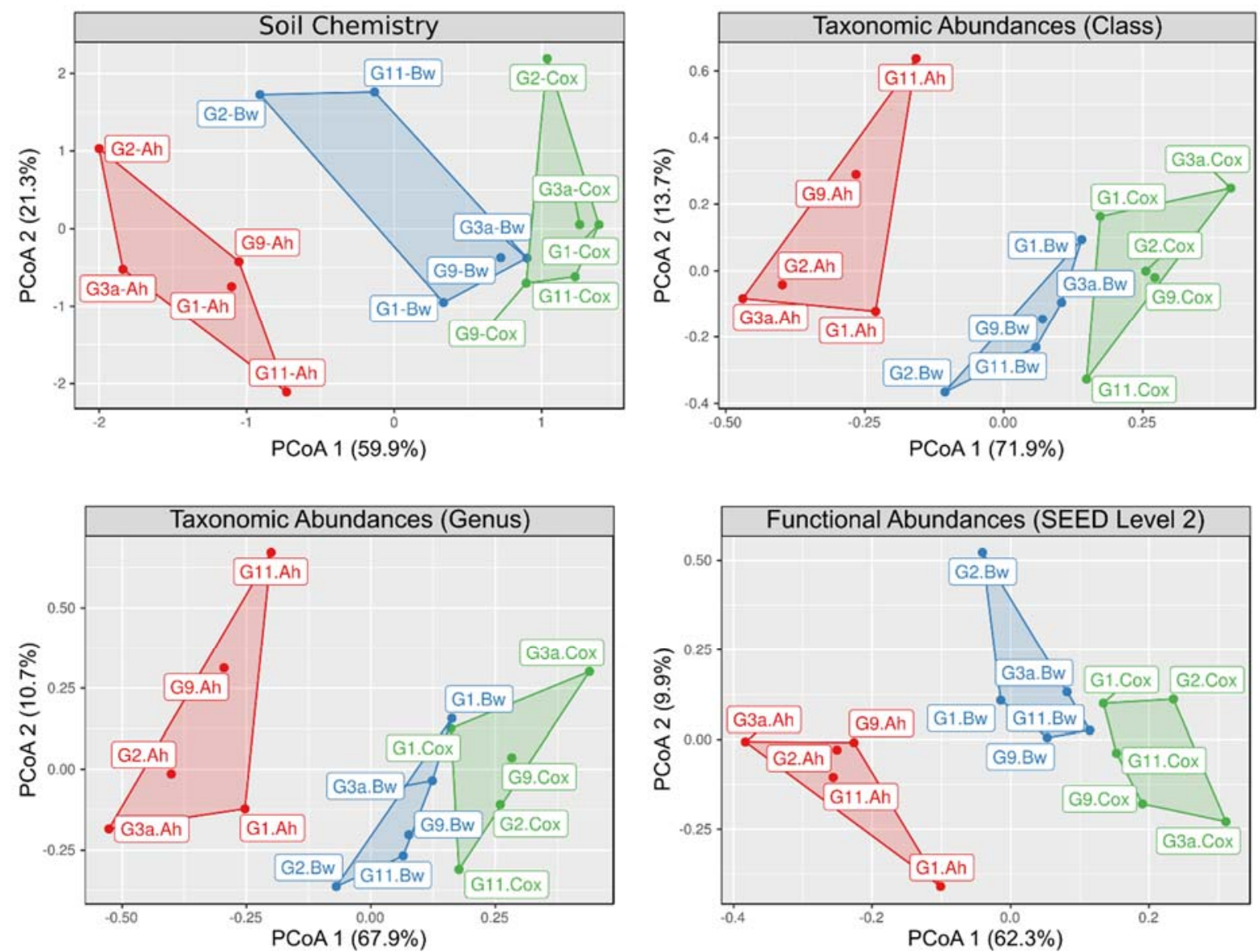

763 Figure 5: PCoA plots of abundance tables at each taxonomic and functional rank. Constrained analysis of principal components was performed on dissimilarity matrices using the function capscale from the package Vegan (Oksanen et al., 2016) in R version 3.4.1 (R Core Team, 2011). In each case the $x$ and $y$ axis represent the first and second principal component axis respectively. Points are coloured by soil horizon and the convex hulls are drawn and highlighted for each horizon grouping. 

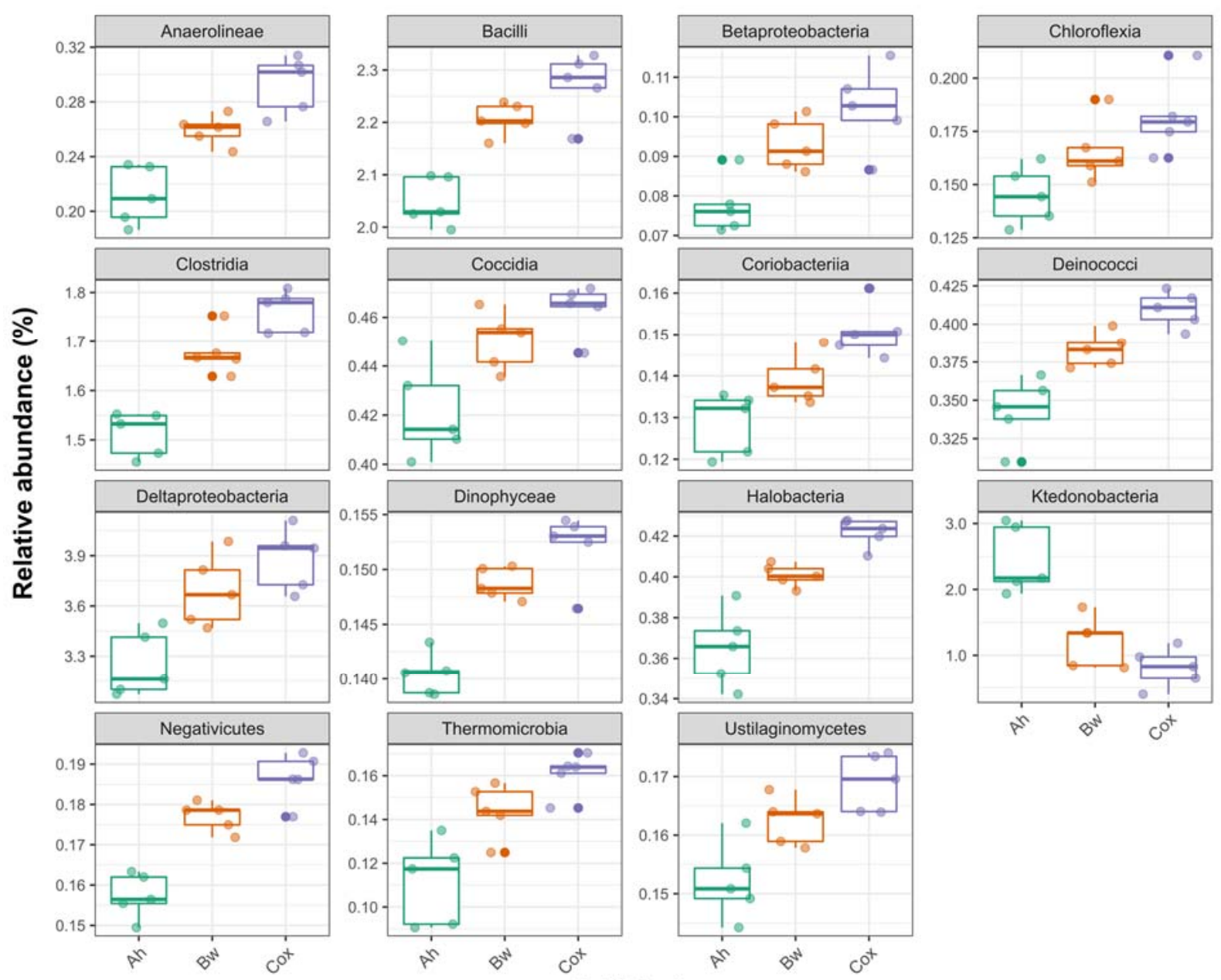

Figure 6: Boxplots showing relative abundance of microbial classes which differed significantly between soil horizons. Relative abundance is expressed as a percentage of the total annotated reads. The bottom and top of the boxes represent the first and third quartiles, with the central band representing the median, whiskers represent 1.5 time the interquartile range according to Tukey's boxplot method (Tukey, 1977). All data points are also plotted as points. 

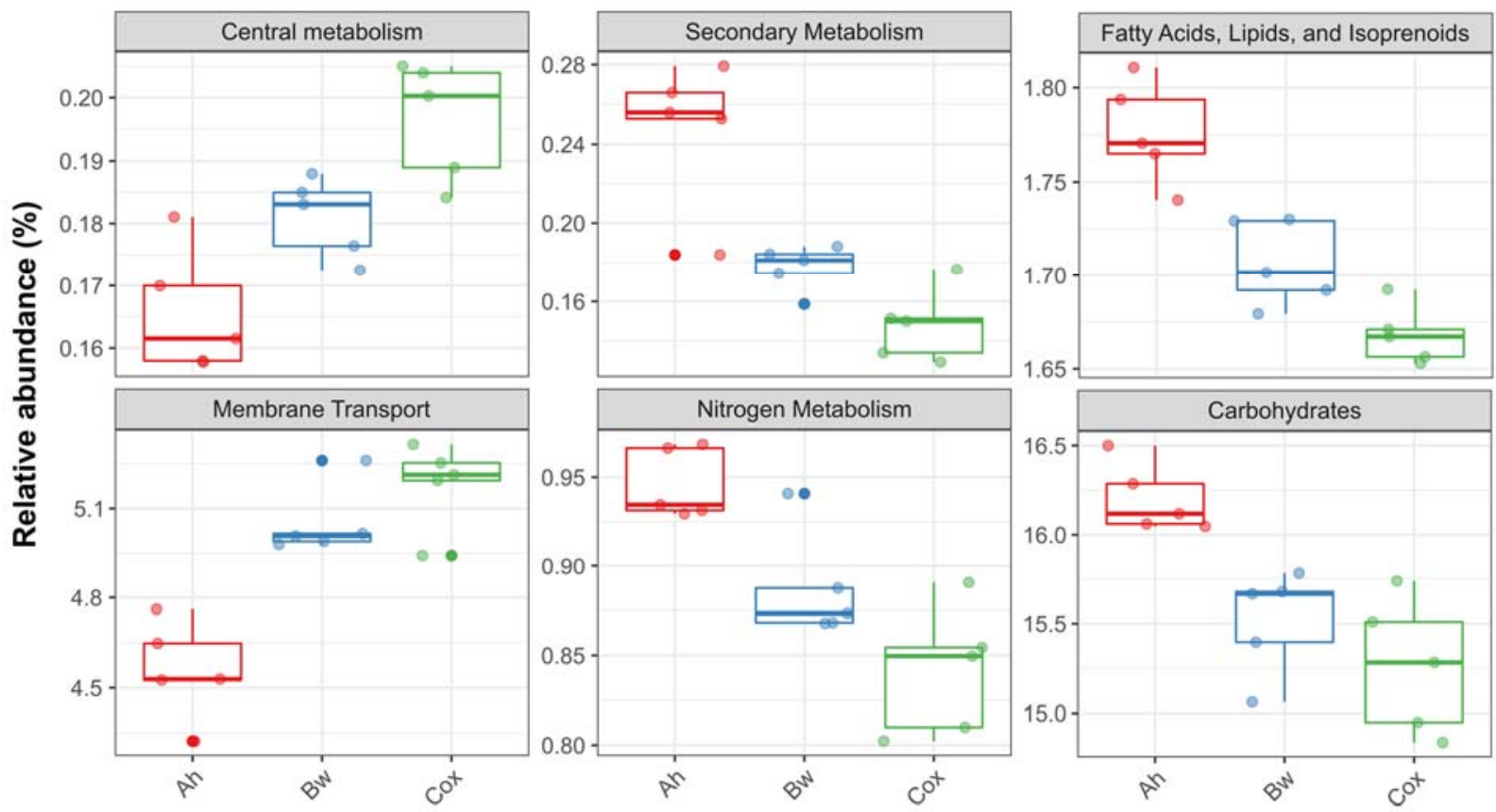

Soil Horizon

Figure 7: Boxplots of relative abundance of SEED level 1 functional categories. Relative abundance is expressed as a percentage of the total annotated reads. The bottom and top of the boxes represent the first and third quartiles, with the central band representing the median, whiskers represent 1.5 times the interquartile range according to Tukey's boxplot method(Tukey, 1977). All data points are also plotted as jittered points.
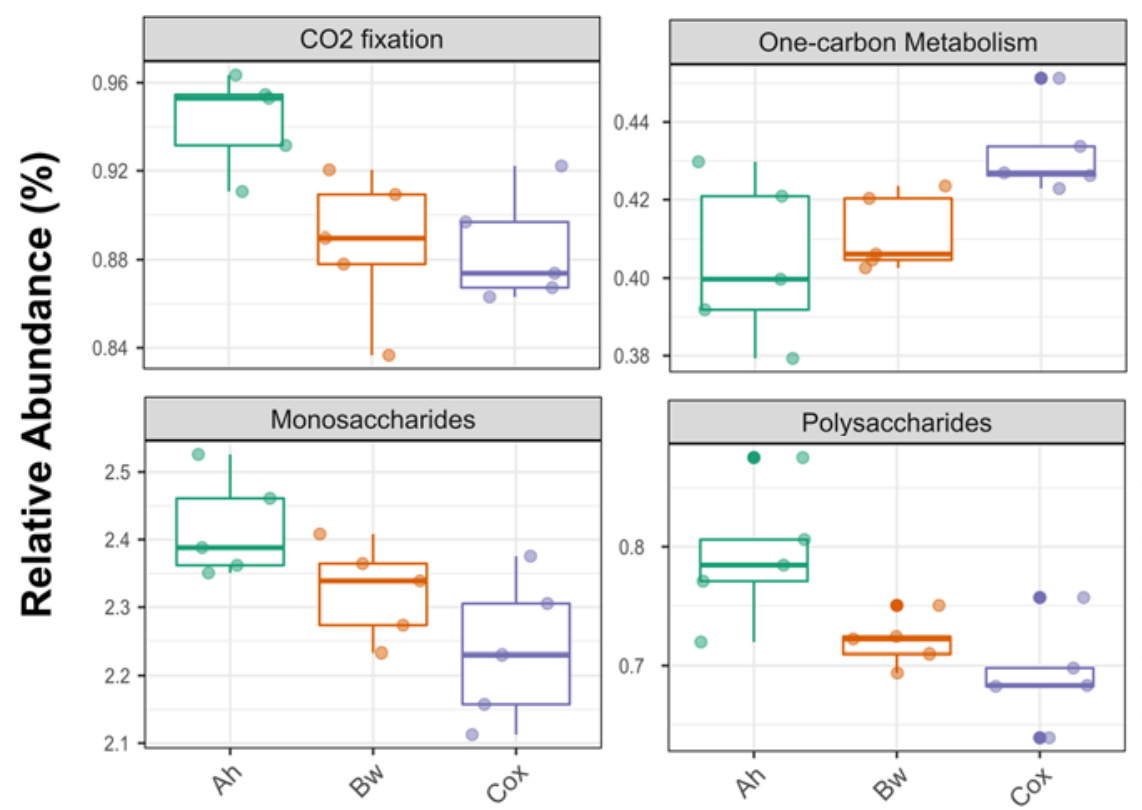

Soil Horizon

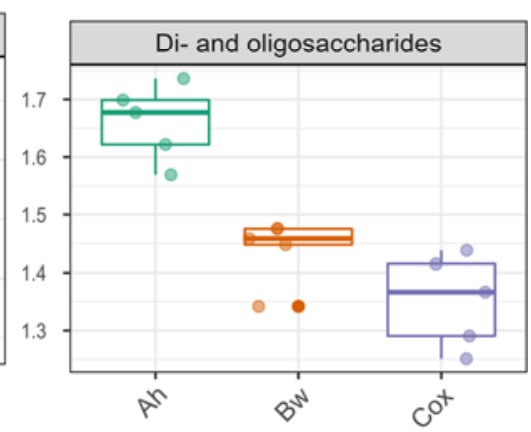

Figure 8: Abundance of SEED level 2 categories related to carbon metabolism. Relative abundance is expressed as a percentage of the total annotated reads. The bottom and top of the boxes represent the first and third quartiles, with the central band representing the median, whiskers represent 1.5 time the interquartile range according to Tukey's boxplot method (Tukey, 1977). All data points are also plotted as points. 
